\title{
Use it responsibly
}

\author{
Gaetano Rocco, MD, FRCSEd
}

\footnotetext{
From the Division of Thoracic Surgery, Thoracic Department, Istituto Nazionale Tumori, IRCCS, Fondazione Pascale, Naples, Italy.

Disclosures: Author has nothing to disclose with regard to commercial support.

Received for publication April 20, 2017; accepted for publication April 21, 2017; available ahead of print May 31, 2017.

Address for reprints: Gaetano Rocco, MD, FRCSEd, Thoracic Department, Division of Thoracic Surgery, Istituto Nazionale Tumori, IRCCS, Fondazione Pascale, Via Semmola 81, 80131, Naples, Italy (E-mail: g.rocco@ istitutotumori.na.it).

J Thorac Cardiovasc Surg 2017;154:687-8

$0022-5223 / \$ 36.00$

Copyright (c) 2017 by The American Association for Thoracic Surgery

http://dx.doi.org/10.1016/j.jtcvs.2017.04.048
}

Under the formidable propulsion exerted by advocates of stereotactic body radiation (SBRT) for early-stage lung cancer, we are all asked at some point to argue the case for surgery in our hospitals or during national or international scientific meetings. ${ }^{1}$ In a time when lobectomy rates are decreasing in favor of sublobar resections and SBRT, ${ }^{2}$ an article like the one in this issue of the Journal by Yerokun and associates ${ }^{3}$ is destined to provide the surgeon with additional ammunition in fueling the heat of the never-ending debate about sublobar resections versus SBRT. ${ }^{4}$ The general impression, however, is that a truce can be called until longterm results of properly devised randomized, controlled trials become available. ${ }^{5}$ In the meantime, sublobar resections are becoming increasingly attractive as the ideal extension of resection for small tumors. ${ }^{6}$ Theoretically, wedge resection is the perfect comparison for SBRT. Wedge resection entails limited parenchymal extension, is typically done for peripheral lesions, is often (but not always) selected for patients considered marginal candidates for surgery, and is done without proper lymphadenectomy at either the hilar or the mediastinal level. SBRT shares most of these features: it targets an area limited to the lung nodule, is preferably performed outside the more central "no fly zone" of the lung, is often offered to patients who are not fit for or refuse surgery, and usually is chosen for those with a mysterious nodal status. ${ }^{5}$ The discrepancies seen in the literature as to the superiority of one treatment relative to the other are generated from the fact that, in the same fashion that SBRT can be somehow "modulated" to fit an individual patient's needs, wedge resection of the lung is performed with varying levels of expertise and appropriateness across the thoracic surgical community. ${ }^{5,7}$ At one end lies the unacceptable wedge resection done systematically for any "small" lung lesions and any degree of impairment of cardiopulmonary function compared with the "norm" without respect for margins, let alone nodal stations. These procedures are almost invariably performed through a classic thoracotomy, sometimes adding insult to injury. This scenario often corresponds to the triumph of

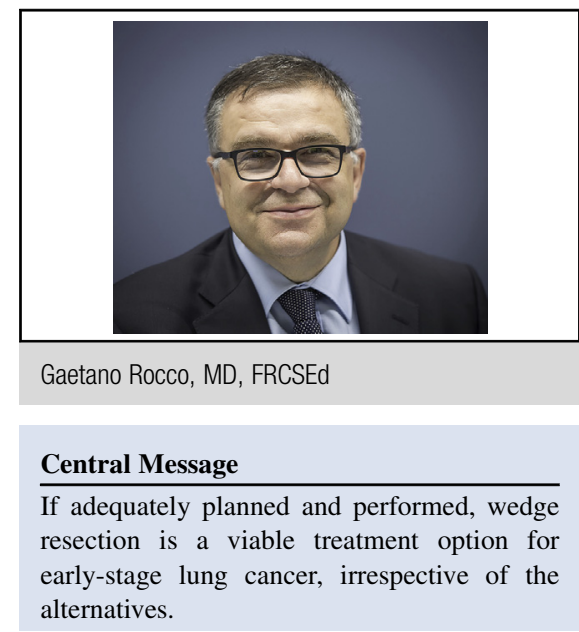

See Article page 675

unbalanced surgical subjectivity..$^{5}$ At the other end of the spectrum lies the wedge resection done thoracoscopically for pure ground glass opacities. This scenario corresponds to a nirvana of the surgical decision-making process, because resection of cancerous ground glass opacities will certainly lead to prolonged survivals.

When very early lung cancer tumors are treated, SBRT and surgery are more frequently compared in terms of overall and disease-free survivals; in the absence of nodal involvement, the differences could be minimal in the first 3 years. ${ }^{5}$ The assessment of cancer-specific survivals may serve as a better surrogate of therapeutic efficacy than these indicators, because it demands a definitive cytohistologic diagnosis of cancer, thus avoiding outcome contamination from treating benign lesions. ${ }^{5}$ In this setting, another criterion that should be taken into consideration when comparing surgical procedures with SBRT is the type of surgical approach used to perform wedge resection, because invasiveness may be a factor in determining posttreatment morbidity, a strong point for refusing surgery in favor of SBRT.

The work by Yerokun and colleagues ${ }^{3}$ is to be commended because it probably is as good as it gets with current data and current limitations, including the lack of information that can still affect treatment choices but that we cannot derive from large databases. Until we will have data from randomized, controlled trials, a carefully implemented early-stage non-small cell lung cancer treatment program should be the aim of every tumor board, supported by a surgical expertise founded on minimally invasiveness and the individualization of patient care according to shared criteria of medical fitness for surgery. ${ }^{5}$ If the latter principles are 
respected, irrespective of the alternatives, wedge resection has a definite role in the therapeutic strategy of earlystage lung cancer-it is up to us surgeons to use it responsibly. ${ }^{8}$

\section{References}

1. Port JL, Parashar B, Osakwe N, Nasar A, Lee PC, Paul S, et al. A propensitymatched analysis of wedge resection and stereotactic body radiotherapy for early stage lung cancer. Ann Thorac Surg. 2014;98:1152-9.

2. McMurry TL, Shah PM, Samson P, Robinson CG, Kozower BD. Treatment of stage I non-small cell lung cancer: what's trending? J Thorac Cardiovasc Surg. 2017; 154:675-86.

3. Yerokun BA, Yang CF, Gulack BC, Li X, Mulvhill MS, Gu L, et al A national analysis of wedge resection versus stereotactic body radiation therapy for stage IA non-small cell lung cancer. J Thorac Cardiovasc Surg. 2017;154: 675-86.

4. Altorki NK, Kamel MK, Narula N, Ghaly G, Nasar A, Rahouma M, et al. Anatomical segmentectomy and wedge resections are associated with comparable outcomes for patients with small cT1N0 non-small cell lung cancer. J Thorac Oncol. 2016;11:1984-92.

5. Rocco G. Narcissus, the beam, and lung cancer. J Thorac Cardiovasc Surg. 2016; 152:338-43.e3.

6. Altorki NK, Yip R, Hanaoka T, Bauer T, Aye R, Kohman L, et al. Sublobar resection is equivalent to lobectomy for clinical stage 1 A lung cancer in solid nodules. $J$ Thorac Cardiovasc Surg. 2014;147:754-62; discussion 762-4.

7. Stiles BM, Kamel MK, Nasar A, Harrison S, Nguyen AB, Lee P, et al. The importance of lymph node dissection accompanying wedge resection for clinical stage IA lung cancer. Eur J Cardiothorac Surg. 2017;51:511-7.

8. D'Amico TA. The best that surgery has to offer. J Thorac Cardiovasc Surg. 2013; 145:699-701. 